\title{
Effects of Peeling with Flexible Alloy Blade on Naked Oats
}

\author{
ZHANG Zheng, WANG Xiaoxi*, MA Sen \\ College of Food Science and Technology, Henan University of Technology, Zhengzhou 450001, China
}

\begin{abstract}
This research reported the effect of peeling naked oats with a peeling machine equipped with the flexible alloy blade. Results showed that the flexible alloy blade could achieve the same effect as traditional abrasive rolls. Furthermore, the new peeling method had hardly damage to the oat kernels. The result of scanning electron microscopy indicated the surface of peeled naked oats by the flexible alloy blade is homogeneous. The gap between the flexible alloy blade and the slotted screen could change the particle sizes of the flours obtained, which differed from traditional peeling machines. In addition, peeling for 15 seconds significantly reduced the microbial contaminants. The removal of outer layer decreased the lipase activity. The technological parameters were optimized by orthogonal $L_{9}\left(3^{4}\right)$ test, the results showed a 30 s peeling time and $2 \%$ second-addition of water contributed to the peeling rate. The texture analysis demonstrate that the hardness of cooked groats decreases obviously after peeling treatments.
\end{abstract}

Keywords: Naked oats; Peeling; Flexible alloy blade; Microbial contaminants; Lipase activity

\section{Introduction}

Naked oats have been the object of extensive studies, because they have a larger amount of total protein, crude fat and a smaller amount of crude fiber compared with other cereals ${ }^{[1]}$. In China, $95 \%$ of oats are naked oats (Avena nuda L.), the others are hulled oats ${ }^{[2]}$. As a result, China has many naked oats to process and consume. In recent years, "oat rice" (peeled naked oat kernels $)^{[3]}$ has become accepted as a novel oat product by Chinese consumers. During the processing of oat rice, peeling technology plays an essential role.

Peeling technology is originated from rice polishing and barley processing, in more recent times, it has been integrated into wheat and oats processing ${ }^{[4]}$. The lipid content and activity of lipase in oats are much higher than other grains ${ }^{[5-6]}$. The lipases can oxidize the lipid into free fatty acids. Lipase activity should be controlled, because it can cause a rancid taste and have other adverse effects ${ }^{[7-8]}$. As most of enzymes are located in the outer layer, the lipase activity could be markedly decreased after peeling ${ }^{[9-10]}$. Harvested grains contain microbial contamination, which may produce hazardous chemicals such as mycotoxins and aflatoxin. These increase the potential health risk ${ }^{[11]}$. The peeling of oats could effectively remove trichomes which is recognized as a health hazardous material closely related to the aluminum content in oats. In addition, peeling can not only reduce the content of microbial contaminants and other potential harmful substance that could be found on the surface of oats, but also affect flour yield and product quality ${ }^{[12-13]}$.

According to the friction and shear force between oat kernel and rolls or screen, oats are peeled to remove part of bran ${ }^{[14]}$.

Received: 19 March 2018 /Accepted: 11 May 2018.

Supported by National Natural Science Foundation of China (No. 31571873), and National College Students Innovation and Entrepreneurship Training Program Project (201710463002).

*Corresponding author. E-mail: wangxiaoxhaut@126.com

CHenan University of Technology 2018

ZHANG Z, WANG X X, MA S. Effects of Peeling with Flexible Alloy Blade on Naked Oats[J]. Grain \& Oil Science and Technology, 2018, 1(3): 131-137.
However, the gap between the roll and screen in conventional peeling machines cannot be changed during running, and oat grains have different sizes and shapes, as the result, larger kernels may be seriously damaged, while smaller kernels may be peeled inadequately. The peeling processing is heterogeneous and this can reduce the quality of oat rice or affect the pre-processing.

This study used innovative technology to adapt the peeling machine. A flexible alloy blade was utilized, instead of abrasive rolls, as the gap between the alloy blade and screen can be changed during the peeling process according to the size of kernels. The method would obviously improve the peeling efficiency and reduce kernel damage rate.

\section{Materials and Methods}

\subsection{Naked Oat Cultivars}

Two samples of Bayou No. 2 oats were used. They were harvested in Zhangjiakou and Chifeng in 2017, respectively. Two sample were cleaned and threshed, then stored at $-18{ }^{\circ} \mathrm{C}$ until analysis.

\subsection{Innovative Peeling Equipment}

The main peeling process was accomplished by the peeling machine, RCMTK-A20 (Rongcheng Corporation, Zhengzhou, China) with the flexible alloy blade. The essential parts were shown in Fig. 1. Each batch was $5 \mathrm{~kg}$. Samples were rotated by the flexible alloy blade after entering the chamber. When a large kernel got through the gap between flexible alloy blade and the slotted screen, flexible alloy blade would change to increase the gap, when a small kernel got through the gap, the flexible alloy blade would decrease the gap. The bran was removed by abrasion between kernel and kernel, kernel and flexible alloy blade, or kernel and the slotted screen. The gap between flexible alloy blade and the slotted screen was dynamic during the whole peeling processing, so the effect of peeling was uniform. We also used a Satake TM05C abrasive mill (Satake Corporation, Hiroshima, Japan) as the control group, each batch was $150 \mathrm{~g}$. 

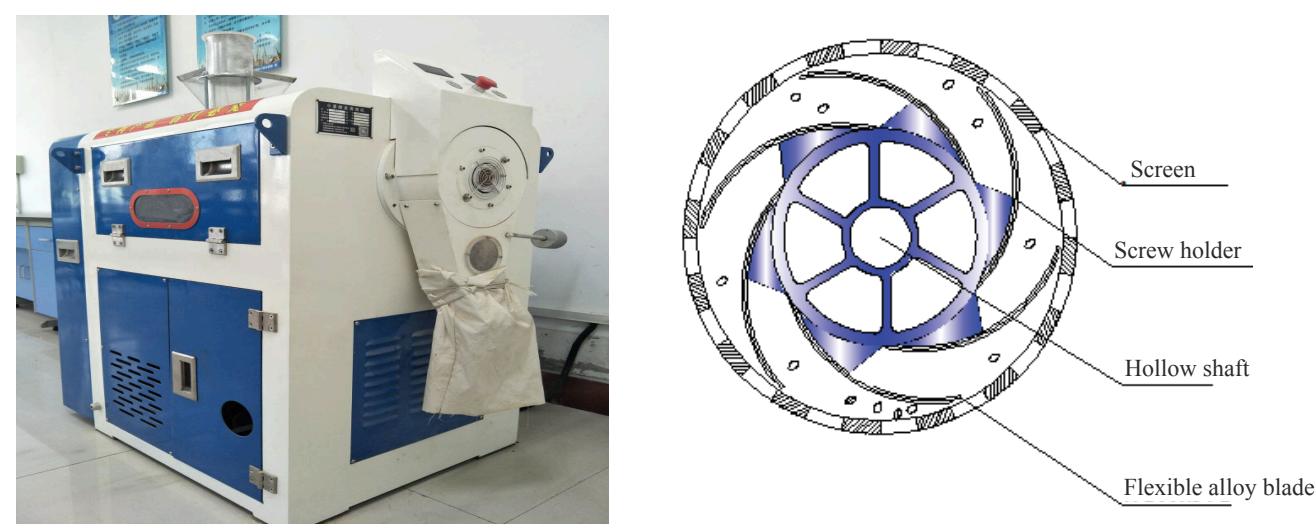

Fig. 1 Appearance and schematic of the peeling machine with the flexible alloy blade

\subsection{Effect of Different Peeling Machines on Peeling Rate and Breakage Rate}

Two naked oat cultivars were peeled by the RCMTK-A20 peeling machine and Satake TM05C abrasive mill. Peeling rate referred to the percentage $(\%, W / W)$, peelings accounting for the naked oat cultivars by weight. The broken kernels were picked out from $20 \mathrm{~g}$ peeled groats, breakage rate was defined as the percentage $(\%, W / W)$, broken kernels accounting for $20 \mathrm{~g}$ peeled groats by weight.

\subsection{Scanning Electron Microscopy (SEM)}

Groats at different degrees of peeling were observed by SEM (Co.S-3400N II, HITACHI, Japan). Groats were pre-treated, fixed and covered with gold, then photographs were taken.

\subsection{Effect of Different Peeling Treatments on Total Number of Bacterial Colony}

After peeling $25 \mathrm{~g}$ groats were added to $225 \mathrm{~mL}$ sterilized saline $(0.8 \%)$, and shaken adequately. The suspension was treated for gradient dilution of $10^{-1}, 10^{-2}$, and $10^{-3}(\mathrm{~V} / \mathrm{V})$. $1 \mathrm{~mL}$ aliquot suspension of every different concentration was inoculated onto aerobic count plates (OASIS BIOCHEM, Guangzhou, China). The total number of bacterial colony was counted and calculated after incubation for $24 \mathrm{~h}$ at $(36 \pm 1)^{\circ} \mathrm{C}$.

\subsection{Effect of Different Peeling Treatments on Lipase Activity}

The lipase activity was determined according to Kwon et al. ${ }^{[15]}, 98 \mu \mathrm{L}$ of triolein as the substrate and lipase of 0.5 $\mathrm{g}$ defatted oat kernel power as the enzyme were mixed, and 330 $\mu \mathrm{L}$ buffer $(0.05 \mathrm{~mol} / \mathrm{L}$ Tris- $\mathrm{HCl}, \mathrm{pH} 7.5$, containing $1 \% \mathrm{~V} / \mathrm{V}$ Triton X-100) was added to the mixture, then mixed thoroughly and form a dough. The dough was incubated at $37^{\circ} \mathrm{C}$ for $1 \mathrm{~h}$. To stop the action, $100 \mu \mathrm{L}$ of $1 \mathrm{~mol} / \mathrm{L} \mathrm{HCl}$ was added. As the control group, $\mathrm{HCl}$ was added immediately without incubation and stirring was maintained. The product, oleic acid, was extracted using a boiling water bath for $5 \mathrm{~min}$ with $5 \mathrm{~mL}$ of hexane. After centrifugation ( $2000 \mathrm{r} / \mathrm{min}, 10 \mathrm{~min}$ ), the absorbance of extracted oleic acid was measured at $715 \mathrm{~nm}$, and compared with an oleic acid standard. The resulting lipase activity was described in units of $\mu \mathrm{mol} / \mathrm{L}$ of oleic acid per hour per gram.

\subsection{Optimization of Peeling Treatment Condition for Oat Rice}

Conditions of the peeling treatment were optimized through an orthogonal $L_{9}\left(3^{4}\right)$ test design. Factors and levels are shown as Table 1. The whole pretreatment was addition of $2 \%$ water $(W / W)$, tempering, second-addition of water, second-tempering time.

\begin{tabular}{cccc} 
Table 1 Factors and levels of the orthogonal $L_{9}\left(3^{4}\right)$ \\
\hline Parameters & \multicolumn{3}{c}{ Level } \\
\cline { 2 - 4 } & 1 & 2 & 3 \\
\hline Peeling time (s) & 10 & 20 & 30 \\
Tempering (h) & 12 & 14 & 16 \\
Second-addition of water (\%) & 1 & 2 & 3 \\
Second-tempering time (min) & 5 & 10 & 15 \\
\hline
\end{tabular}

\subsection{Texture Characteristics of Oat Kernel after Peeling}

Peeled oat kernel was soaked for $30 \mathrm{~min}$, then cooked. The texture characteristics were determined by a texture analyzer (Model: TA. XT. plus, Stable Microsystems, Surrey, UK). The probe was a $25 \mathrm{~mm}$ diameter aluminum cylinder. The running parameters were pre-test speed $10 \mathrm{~mm} / \mathrm{s}$, test speed $0.5 \mathrm{~mm} / \mathrm{s}$, post-test speed $0.5 \mathrm{~mm} / \mathrm{s}$ and $70 \%$ deformation level of the original height.

\subsection{Statistical Analysis}

All results were treated and obtained by Excel software (Microsoft Office Professional Plus 2010, Microsoft, USA), SPSS software (version 15.0, SPSS Inc., Chicago, IL, USA) and origin 85 .

\section{Results and Discussion}

\subsection{Effect of Different Peeling Machines on Peeling Rate}

In this study, two types of machines, the new type of peeling machine with flexible alloy blade and the abrasive mill, were used to peel two naked cultivars. As it is shown in Fig. 2, the peeling rate of Bayou No. 2 was higher than Bayou No. 8. It was likely associated with the degree of bonding between the bran and endosperm in different cultivars. When the same oat kernel was peeled with different peeling machines, the peeling 


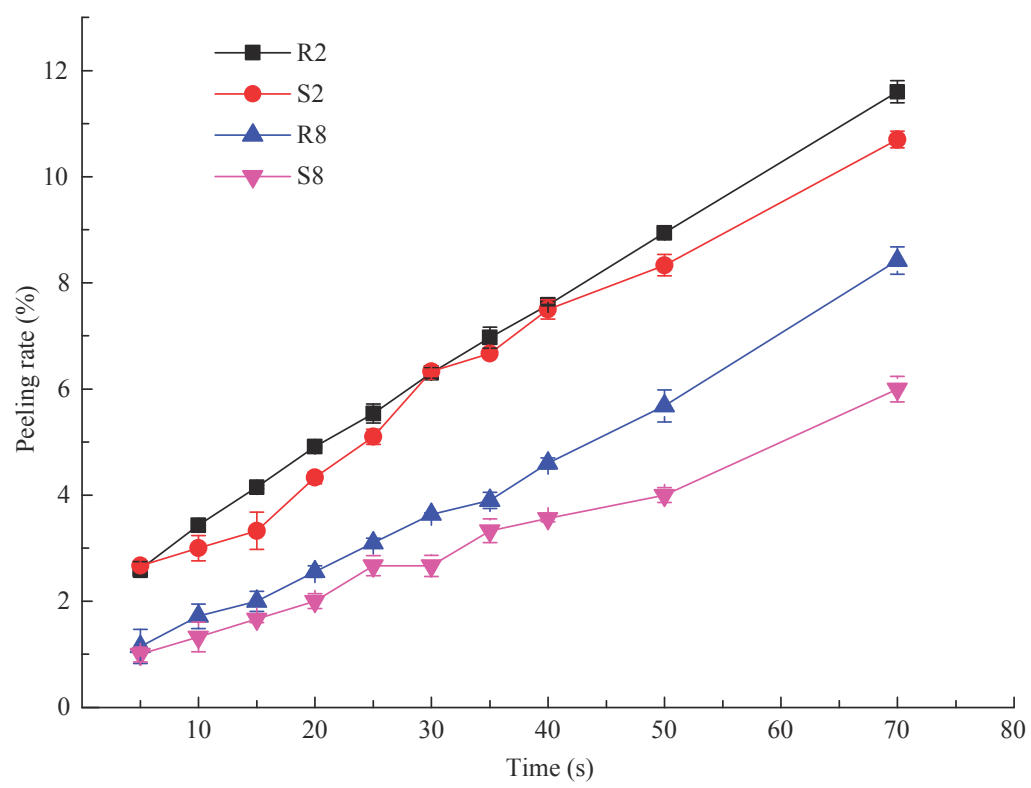

Fig. 2 Peeling rate of different peeling machines

R2: Bayou No. 2 peeled by RCMTK-A20, S2: Bayou No. 2 peeled by Satake TM05C, R8: Bayou No. 8 peeled by RCMTK-A20, S8: Bayou No. 8 peeled by Satake TM05C. The same as below.

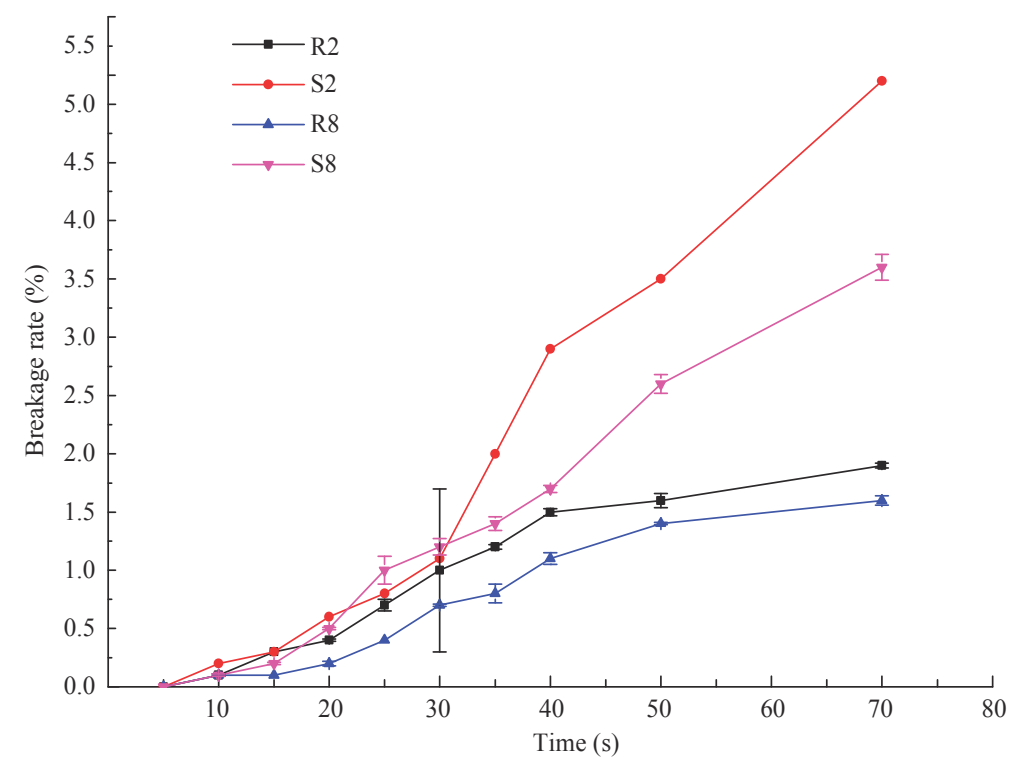

Fig. 3 Breakage rate of different peeling machines

rate of both increased with peeling time. However, the peeling rate of the new peeling machine was slightly higher than the traditional machine. The traditional peeling process was carried out by the abrasion generated by the peeling wheel ${ }^{[4]}$, the main part peeled was the ventral surface, especially from the ridges along the crease towards the end, and the dorsal surface was peeled slightly ${ }^{[13]}$. The ventral part was higher than dorsal part, so when the kernel travelled through the gap between rolls or roll and screen, the ventral part was damaged. However, the smaller kernels could get through the gap without being peeled. The peeling machine with flexible alloy blade could solve the problem effectively, because the gap could increase or decrease according to the size of kernels and meantime, the flexible alloy blade could strip the bran. During the whole peeling process with the innovate peeling theory, it was found breakage rate was lower than the traditional theory (Fig. 3). After 40 s peeling, the breakage rate of traditional theory increased rapidly.

\subsection{Scanning Electron Microscopy}

SEM was used to investigate the peeled kernel for the further and visible effects of peeling treatment. Taking Bayou No. 2 as an example, the surface of kernel without peeling treatment was observed clearly (Fig. 4a), the bran layers, the aleurone layer and endosperm were attached together tightly. Images (from Fig. 4b to Fig. 4e) of groats were peeled by the peeling machine with the flexible alloy blade for different peeling time, Fig. 4f to Fig. 4h were treated by the traditional peeling machine equipped with the abrasive rolls for different times. 

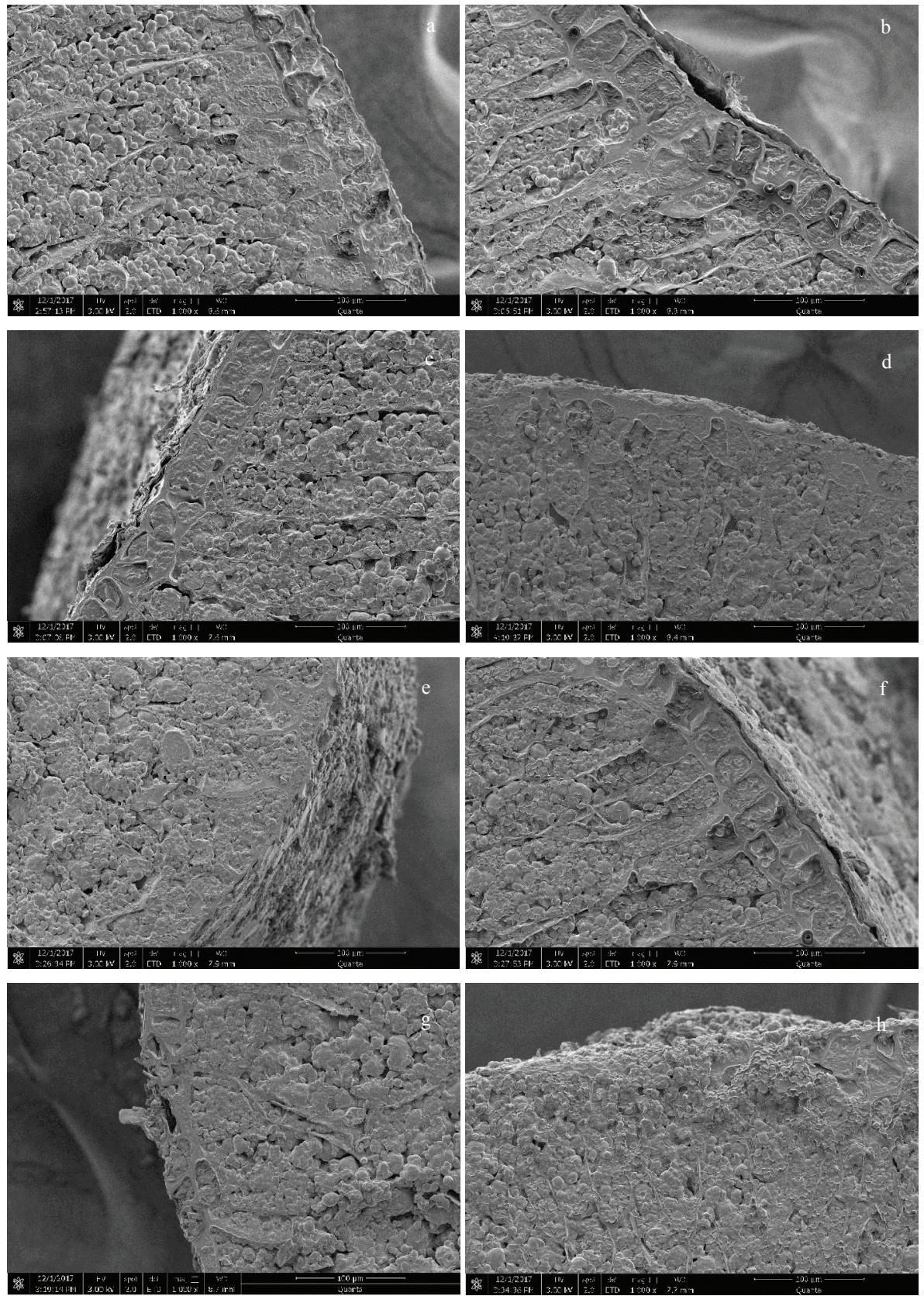

Fig. 4 Scanning electron microscopy images of groats with different peeling time

Note: The bran layers, the aleurone layer and endosperm without peeling treatment (a), the bran layers after peeled with the flexible alloy blade for $5 \mathrm{~s}$ and $25 \mathrm{~s}$ respectively ( $b$ and $c$ ), the aleurone layer after peeled with the flexible alloy blade for $50 \mathrm{~s}(\mathrm{~d})$, the starchy endosperm after peeled with the flexible alloy blade for $70 \mathrm{~s}(\mathrm{e})$, the bran layers after peeled with the abrasive rolls for $5 \mathrm{~s}$ (f), the aleurone layer and endosperm after peeled with the abrasive rolls for $50 \mathrm{~s}$ (g), the starchy endosperm after peeled with the abrasive rolls for $70 \mathrm{~s}(\mathrm{~h})$.

As can be seen in Fig. 4b, after a 5 s peeling, part of the outer layers was raised, but still combined with the aleurone layer. When the peeling time went up to $25 \mathrm{~s}$ (Fig. 4c), the raised bran was moved away and the inner layer was torn up. The process was repeated several times (Fig. 4d), the aleurone layer was engraved, and only the innermost part of the aleurone layer was left. The surface peeled was smooth and homogeneous. After peeling for $70 \mathrm{~s}$, the aleurone layer was heavily damaged and the endosperm was exposed (Fig. 4e). The aleurone layer had a lot of protein $^{[16]}$, the removal of the aleurone layer causes nutrient loss. Peeling with the abrasive rolls for $5 \mathrm{~s}$, led to the outer layer being brushed slightly. During this process, the trichomes accounted for a lot of the peelings, it could act as a pre-cleaning process and avoid irritating the skin, eyes and respiratory ${ }^{[17]}$. It is shown in Fig. 4f, that the bran separated from the kernel was blocky and inhomogeneous. Up to $50 \mathrm{~s}$ peeling (Fig. $4 \mathrm{~g}$ ), its peeled extent was more serious than $70 \mathrm{~s}$ peeling with the flexible alloy blade, and the surface after peeling was uneven. After a $70 \mathrm{~s}$ 
peeling (Fig. 4h), the starchy endosperm was badly destroyed.

On the basis of SEM, it was concluded the peeling process with the abrasive rolls was "violent", the innovative peeling process was "gradual" and "gentle", the peelings were flake-like. The application of the flexible alloy blade to the peeling machine could not only make the peeling effective and energy-saving, but also reduce the breakage to a great extent. This technology achieved the aim to peel accurately. It might improve the flour yield if adapted to wheat peeling as a pre-processing treatment ${ }^{[12]}$.

The bran layers, the aleurone layer and endosperm without peeling treatment (a); the bran layers after peeled with the flexible alloy blade for $5 \mathrm{~s}$ and $25 \mathrm{~s}$, respectively (b and c); the aleurone layer after peeled with the flexible alloy blade for $50 \mathrm{~s}(\mathrm{~d})$; the starchy endosperm after peeled with the flexible alloy blade for $70 \mathrm{~s}(\mathrm{e})$; the bran layers after peeled with the abrasive rolls for $5 \mathrm{~s}$ (f); the aleurone layer and endosperm after peeled with the abrasive rolls for $50 \mathrm{~s}(\mathrm{~g})$; the starchy endosperm after peeled with the abrasive rolls for $70 \mathrm{~s}(\mathrm{~h})$.

\subsection{Effect of Different Peeling Treatments on Total Number of Bacterial Colony}

The results of different peeling treatments on the total number of bacterial colonies is shown in Fig. 5. The microbial contaminants on Bayou No. 2 kernel surface reduced sharply after peeling for $5 \mathrm{~s}$ to $10 \mathrm{~s}$, because a $5 \mathrm{~s}$ to $10 \mathrm{~s}$ peeling removed almost all trichomes, where some microbial contaminants might be located ${ }^{[18]}$. Furthermore, most of microbial contaminants were present on the surface of the kernel, only a few were in the inner part of kernels ${ }^{[19]}$. Therefore, peeling for a short time was sufficient for the reduction of microbial contaminants. The application of the flexible alloy blade produced a faster decrease, which may be due to the larger peeled areas, removal of the outer layer by the abrasive rolls was partial and inhomogeneous. The decreasing trend of Bayou No. 8 was slower, we speculated it was related to the lower peeling rate and the uneven distribution of microbial contaminants on the surface of Bayou No. 8 .

\subsection{Effect of Different Peeling Treatments on Lipase Activity}

The lipase activity decreased with the increasing of peeling time (Fig. 6), furthermore, the lipase activity had declined noticeably after a $35 \mathrm{~s}$ peeling, because the lipase was mainly distributed in the bran and the aleurone layer, peeling is a direct way to inhibit the lipase activity ${ }^{[20-21]}$. The result was consistent with Fig. 2, which also agreed with $\mathrm{Hu}$ et al. ${ }^{[10]}$. However, there was no evident difference between the two peeling types. The factors that might affect the lipase activity is various, such as the distribution, mechanical damage and temperature ${ }^{[22]}$.

\subsection{Optimization of Peeling Treatment Condition for Oat Rice}

Peeling is a critical treatment of oat rice processing. In order to obtain the efficient process parameters for high-quality oat rice and avoid the breakage, the orthogonal $L_{9}\left(3^{4}\right)$ test was designed to optimize the factors considered the most important. According to the results above, the peeling machine with the flexible alloy blade was chosen to carry out the orthogonal test. The results of the text are presented in Table 2. Although the maximum peeling rated was $3.56 \%$, it could not claim the best process parameters were No 9's in Table 1. The k, K, R values were calculated for further determination. Peeling time was the most important factor with a $5.01 \mathrm{R}$ value, then the second-addition of water, second-tempering time and tempering time was the most insignificant in all selected factors. The results above indicated that the optimal conditions for oat rice, peeling time, tempering second-addition of water, second-tempering time, were $15 \mathrm{~s}, 14 \mathrm{~h}$, $2 \%$ and $5 \mathrm{~min}$, respectively. The optimal conditions could ensure the removal of hazardous substances and avoid the loss of nutrients.

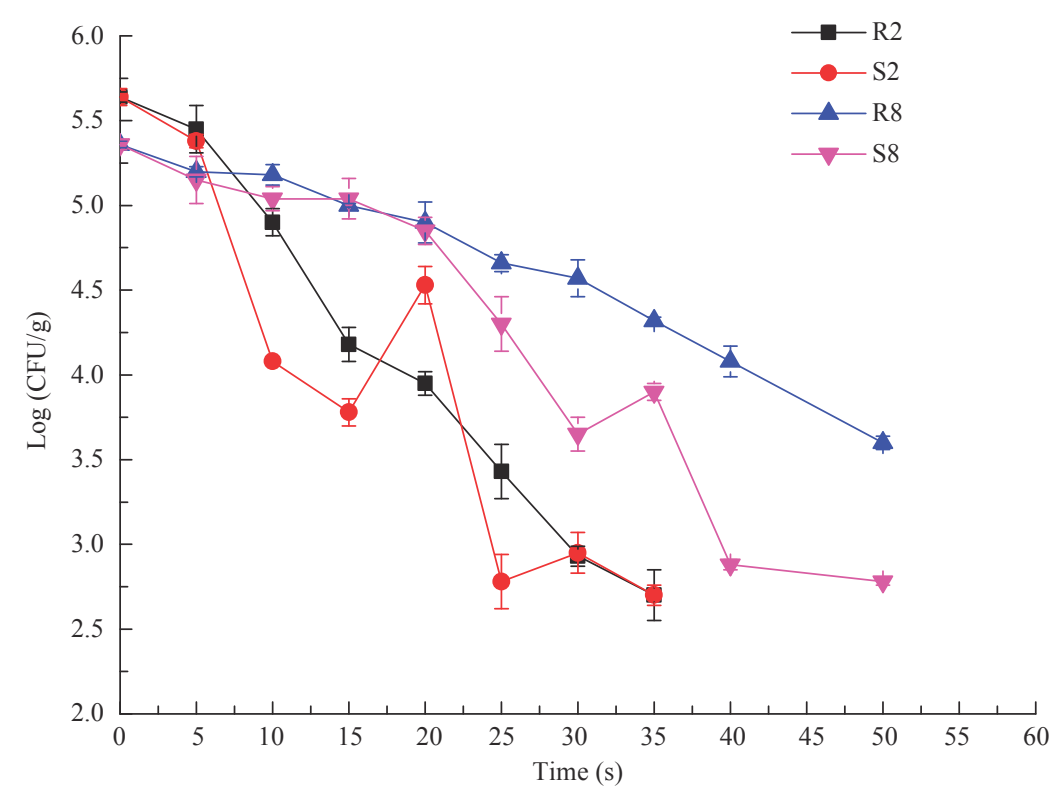

Fig. 5 Microbial contaminants of different peeling treatments 


\subsection{Texture Characteristics of Oat Kernel after Peeling}

The mouthfeel of peeled kernels could influence consumption to a large extent. After optimization, the treated oat kernel (oat rice) was used to examine the texture characteristics of oat rice as the supplement of the orthogonal test (Table 3). Results showed that the oat rice with different peeling conditions had a significant difference in texture $(P<0.05)$. The texture was multidimensional, while hardness was the most important and the most common measured parameter ${ }^{[23]}$. In this study, hardness gradually decreased with the increased peeling rate. When the peeling conditions were peeling time $15 \mathrm{~s}$, tempering time $12 \mathrm{~h}$, second-addition of water $3 \%$, and second-tempering time $10 \mathrm{~min}$ with a $3.5 \%$ peeling rate, the cooked oat rice had the minimum value of hardness. This was mainly caused by the loss of oat bran, which was primarily composed of dietary fiber. The dietary fiber-rich food has a harder texture ${ }^{[24]}$. The cooked oat rice with a $3.56 \%$ peeling rate had the maximal adhesiveness, probably due to the exposed paste starch. Because bran could affect the starch pasting by reducing the absorption by water of the $\operatorname{starch}^{[25]}$. As the peeling rate increased resilience, cohesion and springiness increased first, then decreased, probably due to the removal of bran promoting the starch pasting, while the cooked oat rice lost the support of bran with more removal of bran.

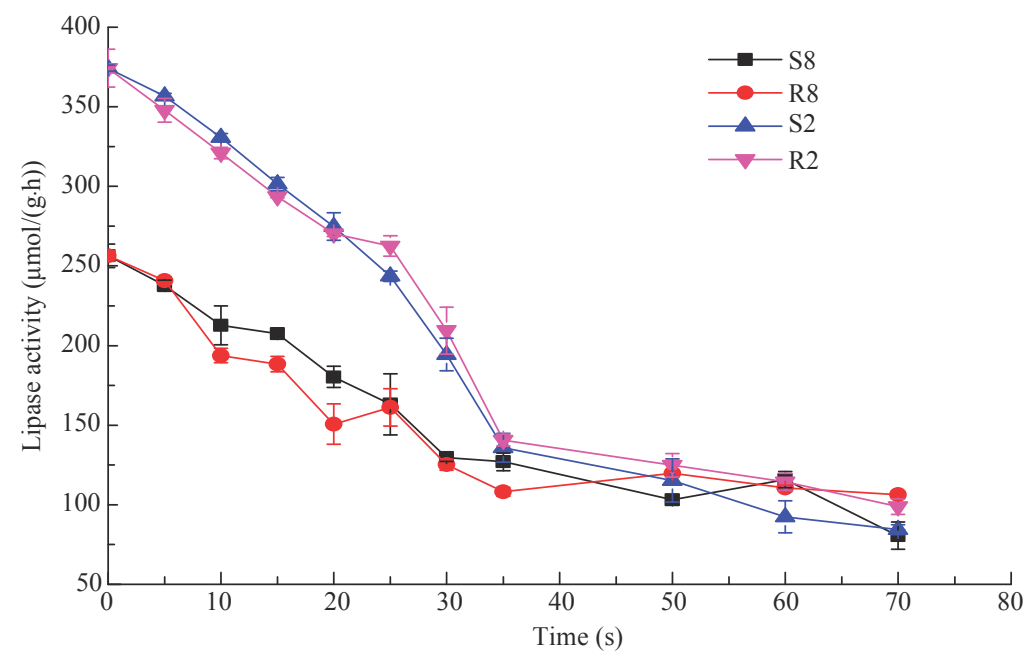

Fig. 6 Lipase activity of different peeling treatments

Table 2 Results of the orthogonal $L_{9}\left(3^{4}\right)$ test

\begin{tabular}{|c|c|c|c|c|c|}
\hline Number & Peeling time $(\mathrm{s}$ ) & Tempering (h) & Second-addition of water $(\%)$ & Second-tempering time $(\min )$ & Peeling rate $(\%)$ \\
\hline 1 & 1 & 1 & 1 & 1 & 1.36 \\
\hline 2 & 1 & 2 & 2 & 2 & 1.59 \\
\hline 3 & 1 & 3 & 3 & 3 & 1.33 \\
\hline 4 & 2 & 1 & 2 & 3 & 2.69 \\
\hline 5 & 2 & 2 & 3 & 1 & 2.57 \\
\hline 6 & 2 & 3 & 1 & 2 & 2.09 \\
\hline 7 & 3 & 1 & 3 & 2 & 3.50 \\
\hline 8 & 3 & 2 & 1 & 3 & 2.23 \\
\hline 9 & 3 & 3 & 2 & 1 & 3.56 \\
\hline $\mathrm{K} 1$ & 4.28 & 7.55 & 5.68 & 7.49 & \\
\hline $\mathrm{K} 2$ & 7.35 & 7.78 & 7.84 & 7.18 & \\
\hline $\mathrm{K} 3$ & 9.29 & 6.98 & 7.40 & 6.25 & \\
\hline $\mathrm{R}$ & 5.01 & 0.80 & 2.16 & 1.24 & \\
\hline
\end{tabular}

Table 3 Results of texture characteristics

\begin{tabular}{|c|c|c|c|c|c|c|c|}
\hline Text no. & Hardness (g) & Adhesiveness (g/sec) & Resilience (\%) & Cohesion & Springiness (\%) & Gumminess (g) & Chewiness (g) \\
\hline 1 & $2300.55 \pm 224.74^{\mathrm{de}}$ & $-2.42 \pm 0.81^{\mathrm{a}}$ & $31.96 \pm 4.75^{\mathrm{bc}}$ & $0.49 \pm 0.05^{\mathrm{cd}}$ & $70.10 \pm 9.51^{\mathrm{a}}$ & $1141.34 \pm 213.98^{c}$ & $811.49 \pm 241.68^{b}$ \\
\hline 2 & $2211.91 \pm 147.70^{\mathrm{de}}$ & $-3.20 \pm 1.07^{\mathrm{a}}$ & $31.51 \pm 2.38^{\mathrm{bc}}$ & $0.49 \pm 0.04^{\mathrm{bc}}$ & $70.54 \pm 10.90^{\mathrm{ab}}$ & $1086.03 \pm 51.18^{\mathrm{c}}$ & $765.55 \pm 120.89^{b}$ \\
\hline 3 & $2205.19 \pm 245.03^{\mathrm{cd}}$ & $-2.48 \pm 0.97^{\mathrm{a}}$ & $31.79 \pm 1.94^{\mathrm{bc}}$ & $1.93 \pm 0.04^{\mathrm{bc}}$ & $72.83 \pm 7.55^{\mathrm{ab}}$ & $1061.06 \pm 113.44^{\mathrm{c}}$ & $776.27 \pm 150.24^{\mathrm{ab}}$ \\
\hline 4 & $2088.06 \pm 138.89^{f}$ & $-2.17 \pm 0.44^{\mathrm{a}}$ & $34.81 \pm 1.47^{\mathrm{c}}$ & $0.53 \pm 0.01^{\mathrm{d}}$ & $92.90 \pm 4.29^{\mathrm{d}}$ & $1381.90 \pm 98.08^{\mathrm{d}}$ & $1283.54 \pm 108.45^{\mathrm{c}}$ \\
\hline 5 & $1990.71 \pm 199.93^{\mathrm{ef}}$ & $-1.84 \pm 0.67^{\mathrm{a}}$ & $39.19 \pm 1.60^{\mathrm{d}}$ & $0.59 \pm 0.01^{\mathrm{e}}$ & $90.38 \pm 6.00^{\mathrm{cd}}$ & $1466.19 \pm 120.64^{d}$ & $1328.34 \pm 170.12^{\mathrm{c}}$ \\
\hline 6 & $1834.49 \pm 159.84^{\mathrm{ab}}$ & $-4.09 \pm 2.01^{\mathrm{a}}$ & $23.94 \pm 1.28^{\mathrm{a}}$ & $0.39 \pm 0.03^{\mathrm{a}}$ & $79.15 \pm 9.76^{\mathrm{abc}}$ & $722.99 \pm 58.32^{\mathrm{a}}$ & $571.50 \pm 75.95^{\mathrm{a}}$ \\
\hline 7 & $1697.84 \pm 124.33^{\mathrm{a}}$ & $-4.09 \pm 4.16^{\mathrm{a}}$ & $28.95 \pm 3.14^{\mathrm{b}}$ & $0.47 \pm 0.03^{\mathrm{bc}}$ & $84.73 \pm 9.19^{\mathrm{bcd}}$ & $807.22 \pm 102.41^{\mathrm{a}}$ & $681.46 \pm 87.48^{\mathrm{ab}}$ \\
\hline 8 & $2083.20 \pm 52.49^{\mathrm{cd}}$ & $-3.05 \pm 1.83^{\mathrm{a}}$ & $29.38 \pm 3.19^{b}$ & $0.47 \pm 0.04^{\mathrm{bc}}$ & $79.44 \pm 5.96^{\mathrm{abc}}$ & $981.81 \pm 103.30^{\mathrm{bc}}$ & $782.23 \pm 126.17^{\mathrm{ab}}$ \\
\hline 9 & $1985.89 \pm 129.44^{\mathrm{bc}}$ & $-7.98 \pm 3.15^{\mathrm{b}}$ & $28.02 \pm 2.44^{\mathrm{b}}$ & $0.44 \pm 0.02^{\mathrm{b}}$ & $75.22 \pm 8.27^{\mathrm{ab}}$ & $878.44 \pm 68.32^{\mathrm{ab}}$ & $658.91 \pm 65.33^{\mathrm{ab}}$ \\
\hline
\end{tabular}

Note: Values in a column followed by different letters were significantly different at $P<0.05$. 
Overall, it is confirmed that oat kernel after peeling has a better sensory evaluation. The processing technology of oats is still incomplete, the peeling machine with the flexible alloy blade could be applied to industrial production to improve the quality of oat rice.

\section{Conclusions}

In this study, after a $70 \mathrm{~s}$ peeling, the peeling rate of flexible alloy blade was $11.6 \%$, which was $0.9 \%$ higher than traditional abrasive rolls and breakage rate was $1.9 \%$. The innovative peeling process is more accurate and it gives homogeneous removal of the outer layer of naked oats without scuffing the endosperm or the aleurone layer as could be seen from SEM. The microbial contaminants were reduced observably after a $15 \mathrm{~s}$ peeling, it was reduced from 440000 to $500 \mathrm{CFU} / \mathrm{g}$. After a $35 \mathrm{~s}$ peeling, the lipase activity decreased from 374.3 to $98.7 \mu \mathrm{mol} /(\mathrm{g} \cdot \mathrm{h})$. As to peeling technology, a $30 \mathrm{~s}$ peeling time and $2 \%$ second-addition of water contributed to the peeling rate. The minimal hardness of cooked oat rice was $1697.84 \mathrm{~g}$ with a $3.5 \%$ peeling rate in the texture analysis.

\section{Conflict of Interest}

The authors declare that there is no conflict of interest.

\section{References}

[1] BIEL W, BOBKO K, MACIOROWSKI R. Chemical composition and nutritive value of husked and naked oats grain[J]. Journal of Cereal Science, 2009, 49(3): 413-418.

[2] QIAN K Y, REN C Z, LI Z G. An investigation on pretreatments for inactivation of lipase in naked oat kernels using microwave heating[J]. Journal of Food Engineering, 2009, 95(2): 280-284.

[3] HU X Z, YAN J T, XING X H. The effects of steaming and roasting treatments on lipase activity and nutritional components of "oat rice" (OR): the peeled naked oat (Avena nuda) kernels[J]. Agricultural Sciences, 2011, 2(2): 56-60.

[4] DEXTER J E, WOOD P J. Recent applications of debranning of wheat before milling $[\mathrm{J}]$. Trends in Food Science \& Technology, 1996, 7(7): 35-41.

[5] HOSENEY R C. Principles of Cereal Science and Technology. A General Reference on Cereal Foods[M]. 1986.

[6] O'CONNOR J, PERRY H J, HAEWOOD J L. A comparison of lipase activity in various cereal grains $[\mathrm{J}]$. Journal of Cereal Science, 1992, 16(2): 153-163.

[7] LEHTINEN P, KAUKOVIRTA-NORIA A. CHAPTER 9-Oat lipids, enzymes, and quality[J]. Oats, 2011: 143-156.

[8] LEHTINEN P, KIILIAINEN K, LEHTOMAKI I, et al. Effect of heat treatment on lipid stability in processed oats[J]. Journal of Cereal Science, 2003, 37(2): 215-221.

[9] MATLASHEWSKI G J, URQUHART A A, SAHASRABUDHE
M R, et al. Lipase activity in oat flour suspensions and soluble extracts[J]. Cereal Chemistry, 1982, 59(5): 418-422.

[10] HU X Z, XING X H, REN C Z. The effects of steaming and roasting treatments on $\beta$-glucan, lipid and starch in the kernels of naked oat (Avena nuda)[J]. Journal of the science of food and agriculture, 2010, 90(4): 690-695.

[11] BOTTEGA G, CECCHINI C, D'EGIDIO M G, et al. Debranning process to improve quality and safety of wheat and wheat products[J]. Tecnica Molitoria International, 2009, 60(10/A): 79-88,

[12] BOTTEGA G, CARAMANICO R, LUCISANO M, et al. The debranning of common wheat (Triticum aestivum, L.) with innovative abrasive rolls[J]. Journal of Food Engineering, 2009, 94(1): 75-82.

[13] WANG R, KOUTINAS A A, CAMPBELL G M. Effect of pearling on dry processing of oats[J]. Journal of Food Engineering, 2007, 82(3): 369-376.

[14] MAHFOUF M, CHEN M Y, LINKENS D A. Adaptive weighted particle swarm optimisation for multi-objective optimal design of alloy steels[C]// Parallel problem solving from Nature-PPSN Viii International Conference. Birmingham, 2004: 762-771.

[15] KWON D Y, RHEE J S. A simple and rapid colorimetric method for determination of free fatty acids for lipase assay[J]. Journal of the American Oil Chemists' Society, 1986, 63(1): 89-92.

[16] PETERSON D M, SAIGO R H, HOLY J. Development of oat aleurone cells and their protein bodies[J]. Cereal Chemistry, 1985 62(5): 366-371

[17] BURROWS V D, MCDIARMID G, MARDER T. Gene controlling reduced trichomes on oat groats[J]. Canadian Journal of Plant Science, 2001, 81(3): 413-414.

[18] LACA A, MOUSIA Z, DIAZ M, et al. Distribution of microbial contamination within cereal grains[J]. Journal of Food Engineering, 2006, 72(4): 332-338.

[19] PAVLOVICH-ABRIL A, ROUZAUD-SANDEZ O, TORRES P, et al. Cereal bran and wholegrain as a source of dietary fibre: technological and health aspects[J]. International Journal of Food Sciences \& Nutrition, 2012, 63(7): 882-892.

[20] MILLER S S, FULCHER R G, WEBSTER F H, et al Microstructure and Chemistry of the Oat Kernel[M]// Oats: Chemistry and Technology. 2 Edn. Elsevier Inc., 2011: 77-94.

[21] URQUHART A A, ALTOSAAR I, MATLASHEWSKI G J, et al. Localization of lipase activity in oat grains and milled oat fractions[J]. Cereal Chemistry, 1983, 60(2): 181-183.

[22] EKSTRAND B, GANGBY I, AKESSON G. Lipase activity in oats-distribution, $\mathrm{pH}$ dependence, and heat inactivation[J]. Cereal Chemistry, 1992, 69(4): 379-381.

[23] MEULLENET J F, LYON B G, CARPENTER J A, et al Relationship between sensory and instrumental texture profile attributes[J]. Journal of Sensory Studies, 1998, 13(1): 77-93.

[24] SAKAMOTO K, SHIBATA K, ISHIHARA M. Decreased hardness of dietary fiber-rich foods by the enzyme-infusion method[J]. Journal of the Agricultural Chemical Society of Japan, 2006, 70(7): 1564-1570.

[25] HAMBERG O, RUMESSEN J J, GUDMAND-HOYER E. Inhibition of starch absorption by dietary fibre. A comparative study of wheat bran, sugar-beet fibre, and pea fibre[J]. Scandinavian Journal of Gastroenterology, 1989, 24(1): 103-109. 